\title{
ELEIÇÕES, POLÍTICA EXTERNA E INTEGRAÇÃO REGIONAL ${ }^{1}$
}

\author{
Janina Onuki
}

\author{
Amâncio Jorge de Oliveira
}

\begin{abstract}
RESUMO
O artigo analisa a relação entre regimes políticos domésticos e integração regional. O argumento central é que a tese que indica que uma convergência política maior com outros regimes de esquerda da região impulsionará o aprofundamento da integração sul-americana embute um paradoxo ainda não explorado nos debates. Embora seja defensável a idéia de que governos de esquerda tenham maior propensão a conferir apoio político ao regionalismo sul-americano, é igualmente verdadeira a idéia de que regimes presidencialistas de esquerda são menos propensos à supranacionalização de normas e à cessão de soberania a instâncias supranacionais. $O$ artigo apresenta breve revisão da literatura a respeito da relação entre política doméstica (regimes políticos e partidários) e produção da política externa e, com respaldo nessa discussão, analisa o tema dos acordos comerciais nas eleições sul-americanas, com ênfase no caso brasileiro.
\end{abstract}

PALAVRAS-CHAVE: integração regional; política externa; eleições; América Latina; governos de esquerda.

\section{INTRODUÇÃO}

Diferentemente do que acontece em países desenvolvidos, particularmente nos EUA, a política externa não costuma ser tema central em processos eleitorais nos países latino-americanos. Ainda que seja um tema amplamente discutido ao longo das campanhas, não chega a ser fator determinante direto do voto. Em outros termos, política externa não dá, nem tira voto ${ }^{2}$. $\mathrm{O}$ máximo que se pode imaginar é que a política externa jogue um papel bastante indireto na decisão do

\footnotetext{
1 Os autores agradecem ao pesquisador Pedro Feliu Ribeiro pela organização dos dados sobre votações nominais no poder Legislativo chileno para temas de política externa. Agradecem também a Manoel Galdino e Karoline Antunes, pesquisadores do Centro de Estudos das Negociações Internacionais da Universidade de São Paulo (Caeni-USP), pela ajuda na obtenção de dados e debates que indiretamente contribuíram para elaboração deste artigo. O resultado, como de praxe, é de nossa inteira responsabilidade.

2 Precisamente por não ser um tema politizado na sociedade a ponto de influencuar a decisão de voto eleitoral, o Legislativo brasileiro tem "delegado" a política externa ao Executivo, conforme Soares de Lima e Santos (2001). Ao promover esta delegação, perde-se a possibilidade de que o próprio Legislativo atue como um conscientizador da sociedade civil em temas de política internacional, gerando-se assim um círculo negativo de apatia política em temas internacionais. Nessa mesma linha de argumentação está Amâncio Oliveira (2003).
}

eleitor, como um dos elementos de um programa de governo mais amplo. Esta baixa relevância de temas internacionais na decisão do eleitor explica, em grande medida, o comportamento reiteradamente pacífico do poder Legislativo em matérias internacionais.

Em recentes disputas eleitorais (Brasil, outubro de 2006; México, julho de 2006; Chile, dezembro de 2005 e Peru, abril de 2006), contudo, o tema dos acordos comerciais, especialmente dos acordos bilaterais ou regionais envolvendo os EUA, foi alçado ao primeiro plano do debate político. Nos casos do México e do Peru assistiu-se a uma polarização ainda mais clara, comparativamente aos demais países, de posicionamento entre distintos setores políticos e de grupos de interesse em torno do tema dos tratados comerciais.

Embora seja precoce afirmar, sem o respaldo de pesquisas empíricas sistemáticas, que a política externa - seja política comercial no sentido mais amplo ou política de integração regional de modo mais específico - tenha se tornado determinante do voto, é válido dizer que a centralidade que esses temas ganharam no debate não tem precedente histórico. No marco desta sensibilização política, difunde-se, nos meios acadêmicos, diplomáticos e jornalísticos, a tese de que a convergência de governos de esquerda na América do Sul ampliaria significativamente as perspectivas da integração regional. 
A análise acadêmica que sistematiza com mais nitidez relações entre espectros político-ideológicos e apoio à integração regional foi elaborada por Fabiano Santos. A correlação positiva entre governos de esquerda e propensão à integração regional é construída por Santos por meio de um conjunto de argumentos. Seu ponto de partida é o da centralidade da integração regional na viabilidade dos governos de esquerda do continente: "Mas por que o tema da integração regional é parte do problema mais geral da viabilidade de governos de esquerda? Uma boa maneira de se tentar uma resposta é o de formular uma outra pergunta: seria mera coincidência a postura próintegração dos governos eleitos recentemente, de inclinação esquerdista? O fato é que as vantagens e problemas de uma ação em bloco das nações sul-americanas voltaram à agenda, e isto coincidiu com a vitória de presidentes de esquerda nestes países" (SANTOS, 2006, p. 2).

O esquema analítico proposto e que fundamenta a tese de Santos é dicotômico. Forças de centro-direita sustentariam uma integração de cunho comercial, no marco de uma reversão forte de apoios societais a projetos neoliberais encampados durante a década de 1990. Sustentariam. ainda, a redução da intervenção do Estado na Economia (noção de Estado mínimo), num contexto em que a integração depende de investimentos estatais, particularmente na área de infra-estrutura. No espectro oposto, para governos de centro-esquerda, a integração regional teria um cunho desenvolvimentista, de apoio à intervenção estatal como indutor da interdependência, especialmente da integração física e energética, além de uma visão não comercial (societal e político-estratégica) dos esforços integrativos regionais.

O objetivo deste artigo é mostrar que o vínculo entre governos de esquerda e sucesso da integração sul-americana precisa, num conjunto de dimensões, ser qualificado. $\mathrm{O}$ argumento defendido é de que os governos de esquerda que emergiram na região, especialmente aqueles com orientações nacionalistas mais acentuadas, têm maior propensão a suportar abordagens intergovernamentalistas nos processos de integração regional, o que dificulta a estabilização e consolidação desses processos. Por trás desta tendência estaria a preocupação dos governos nacionalistas de esquerda em evitar perdas de graus de liberdade em termos de manejo de políticas in- dustriais em decorrência de supranacionalização de normas domésticas.

$\mathrm{O}$ artigo subdivide-se em duas partes principais, além desta. A primeira apresenta breve revisão da literatura a respeito da relação entre regimes políticos domésticos e política comercial. Com respaldo nesta discussão, a segunda parte analisa o tema dos acordos comerciais nas eleições sulamericanas, com ênfase nos casos brasileiro, mexicano e chileno.

\section{POLÍTICA DOMÉSTICA E POLÍTICA EX- TERNANALITERATURA}

Uma ampla literatura destaca o papel das instituições domésticas no processo de formação de preferências, ou na formatação do interesse nacional. Num nível mais amplo, alguns estudos procuram correlacionar tipos de regimes políticos e maior ou menor propensão à assunção de acordos internacionais (GAUBATZ, 1996; VERDIER, 1998; REMMER, 1998; MANSFIELD, MILNER \& ROSENDORFF, 2000; SIMMONS, 2000). Tais estudos tendem a identificar correlações positivas entre democracia e livre-comércio, assim como vínculos entre regimes autocráticos e modelos autárquicos de comércio.

$\mathrm{O}$ argumento geral desses estudos é razoavelmente esquemático. Bueno de Mesquita (2000), por exemplo, parte do pressuposto de que os regimes autocráticos tendem a proteger setores ineficientes da Economia, que não sobreviveriam caso fossem expostos à concorrência internacional. Na medida em que são regimes politicamente fechados, os regimes autocráticos precisam, para sua sobrevivência política, prestar contas apenas a um círculo restrito da elite do país. Com efeito, autocracias tenderiam a ter coalizões vencedoras (winning coalitions) pequenas. Não são afetados, assim, com o fato de que a liberalização econômica pode ser benéfica a um conjunto mais amplo da sociedade - por conta da redução da inflação e diminuição de preços graças à competição de importados, por exemplo -, dado que sua accountability está voltada para um círculo muito restrito da sociedade.

Em regimes democráticos, por outro lado, a lógica seria precisamente inversa. A sobrevivência do governo é dependente de apoio mais amplo da sociedade. A intervenção discricionária em favor de um grupo restrito de agentes econômicos à custa de bases mais amplas desembocaria em 
penalização política. Dado que a winning coalition é mais ampla, a tendência é de que os regimes democráticos optem por modelos liberais.

Infelizmente a aplicabilidade dessas correlações é maior nos casos extremos de regimes políticos: democracias versus autarquias. A correlação para níveis de classificações mais desagregadas (subtipos de regimes políticos) é mais complexa, e menos conclusiva. Ainda, algumas anomalias são dificilmente explicáveis, tais como a instauração dos modelos liberais chileno e turco na década de 1970 em meio a regimes autocráticos.

Outro tema de difícil generalização diz respeito ao fato de que a ampliação de coalizões vencedoras potenciais pode jogar um papel antagônico na formação de preferências internacionais. Isso porque na formação de preferências internacionais, países democráticos necessariamente precisam construir consensos mais amplos, sem o que um acordo comercial não se consolida. No sentido oposto, num regime autocrático o número de pontos de veto da cadeia para a assunção de um acordo comercial é pequeno, tornando todo o processo mais célere.

Deve-se a Tsebelis a incorporação da análise de jogadores de vetos, para além da dicotomia simples democracia-autocracia, no processo decisório político. Segundo o autor, "um veto player é um ator individual ou coletivo cuja concordância (pela regra da maioria no caso dos atores coletivos) é requerida para tomar a decisão de mudar uma política" (TSEBELIS, 1995, p. 15). A conexão entre jogadores de vetos e democracias é direta, na medida em que estes regimes têm mais pontos de vetos do que as autocracias. Se tomarmos a assinatura de acordos comerciais, uma mudança política esperada é que a ampliação do número de veto players amplie a propensão à "estabilidade política".

O processo decisório da União Européia foi utilizado por Tsebelis como exemplo do papel das instâncias de veto na produção de políticas. O autor demonstra que a produção de normas é função da capacidade de veto de instâncias institucionais (Comissão Européia, Parlamento Europeu e Conselho Europeu), assim como é função da capacidade de controle de agenda de cada uma dessas instâncias burocráticas (TSEBELIS, 2001). Neste esquema analítico, distintamente das abordagens neofuncionalistas e intergovernamentalistas da integração regional, o desenho institucional é tomado como variável independente, que modula o comportamento e preferência dos atores.

Neste mesmo campo, merece menção, pela sistematicidade com que aborda vínculos entre constrangimentos domésticos e política externa, o trabalho de Rogowski. Este autor defende que modelos institucionais variam e esta variação afeta, de forma independente, a "contestação, formulação e execução da política externa em pelo menos cincos aspectos fundamentais: viés da politica; credibilidade dos compromissos; coerência e estabilidade das políticas; mobilização e projeção de poder e estratégias dos atores" (ROGOWSKI, 1999, p. 118). Analisa essas variações institucionais, tomadas como variáveis independentes do modelo, em três níveis: padrão de franchise (grupos que realmente influenciam o processo político); sistema de representação (se os representantes são escolhidos pelo universo de eleitores ou de forma restrita) e regras de decisão (grau de centralização decisória).

Em linhas gerais as conclusões de Rogowski acompanham Tsebelis como, por exemplo, na correlação positiva entre ampliação de pontos de veto no processo decisório e postura conservadora (de status quo) na formulação de políticas externas. Mas aportam elementos inovadores como a idéia de que sistemas políticos regionalmente fragmentados ou com um número maior de pontos de vetos geram políticas externas incoerentes ou instáveis.

Também vale mencionar nesta mesma linha o trabalho Joe Hagan (1995). Este autor também leva em consideração, no esforço de vincular fatores institucionais domésticos e política externa, a estrutura do regime político e o tipo de unidades últimas de decisão do processo político. Porém, diferentemente de outros trabalhos, foca atenção principalmente no tipo de relação que os regimes políticos estabelecem com a oposição no processo de formulação de política externa. Os regimes são mais ou menos sensíveis à oposição, e a forma como esta relação se estabelece tem impacto nos resultados (outcomes) políticos.

Esquematicamente, Hagan assevera que os regimes com posturas acomodacionistas, ou seja, que lidam com a oposição por meio de barganha e evitando confronto, tendem a ser menos propensos à tomada de risco em política externa. No 
sentido oposto, os regimes que optam por ampliar consensos e reforçar a legitimação de suas políticas tendem a ser mais tomadores de risco. No campo intermediário, regimes que optam por posturas de isolamento da oposição tendem a produzir políticas externas mais ineficazes (equivalente funcional de políticas instáveis ou não ratificadas domesticamente).

Para além do desenho institucional no processo decisório em política comercial, outros fatores são mobilizados no sentido de compreender-se o apoio à integração regional, tais como a dimensão macroeconômica, no campo de estudo da Economia Política Internacional, e a dimensão ideológico-político-partidária. Sobre a primeira dimensão vale mencionar os estudos de Bardwell (2000) e Henisz \& Mansfield (2006). O argumento central de Henisz e Mansfield é de que as condições macroeconômicas são determinantes no padrão de apoio aos processos integrativos. Crise econômica e elevação da taxa de desemprego provocam erosão importante no apoio doméstico à integração econômica. Bardwell faz o mesmo raciocínio ao relacionar apoio do Legislativo e situação econômica do distrito que o legislador representa. Em ambos os casos, o processo eleitoral serve como elemento catalisador dos sentimentos sociais a respeito da liberalização comercial.

No campo dos estudos político-partidários, são representativos os trabalhos coordenados por Gary Marks $(2002 ; 2006)$. Esses autores procuram tomar o espectro político-partidário como fator preditivo do apoio político à integração européia. Por meio de estudos empíricos chegam à conclusão de que o contínuo ideológico é um potente fator explicativo do posicionamento em relação à União Européia. Mais do que isso, concluem que os extremos do espectro ideológico, ou seja, extrema-esquerda e extrema-direita adotam atitudes antiintegração regional. Ao passo que o apoio mais contundente à integração parte dos partidos localizados no centro do espectro político.

Como se verá, esses achados são condizentes com a interpretação aqui defendida de que posicionamento político-ideológico de esquerda, particularmente numa faixa nacionalista, não se traduz necessariamente em apoio à integração. $\mathrm{E}$ isso deve-se ao fato de que posturas nacionalistas estão localizadas precisamente nos extremos do espectro político partidário.

\section{ACORDOS COMERCIAIS E PROCESSOS ELEITORAIS NAAMÉRICA LATINA}

Conforme já assinalado, a polarização política em torno do tema "acordos comerciais" é um fenômeno recente e crescente na América Latina. Somente pesquisas de opinião junto ao eleitorado da região serão capazes de capturar o peso dos acordos comerciais na decisão do voto. Porém já é possível verificar, com base em novas pesquisas empíricas, que esse tema começa a tensionar o espectro político-partidário dos países, seja no marco das próprias campanhas eleitorais, seja no campo dos processos de implementação dos acordos no plano do Legislativo. Esta polarização pode também, per si, ser considerada uma novidade no cenário político dos países. Tradicionalmente, as diferenças de posicionamento partidário em relação às questões de política externa eram apenas marginais. A politização atual, ao contrário, é nítida.

O Chile é um caso emblemático. De todos os países da América do Sul, o Chile foi o que fez uma opção mais clara quanto à abertura econômica e estabelecimento de acordos comerciais como parte de sua estratégia de internacionalização econômica. Além de inúmeros acordos comerciais, firmou acordo bilateral com os EUA, incorporando inclusive compromissos internacionais, tradicionalmente rechaçados por países como o Brasil, tal como o acordo de investimento e direito de propriedade intelectual, em bases mais profundas do que o que já está consolidado no âmbito da Organização Mundial do Comércio (OMC).

Em que pese clara inclinação da elite chilena pela integração do país a economias desenvolvidas, assistiu-se também no Chile a um processo de tensionamento político-partidário de acordos comerciais. É o que demonstra a Tabela 1, relacionada ao posicionamento dos deputados chilenos em relação a um projeto de lei que propunha a renúncia do acordo de complementação econômica firmado entre o Chile e o Mercosul. Observa-se, nesta tabela, que o grau de apoio à proposta é condicionado pela orientação político-partidária do legislador. Dentre os deputados de centro-esquerda que compõem a base do atual governo, apenas um representante votou favoravelmente à proposta, contra 40 posicionados contrariamente à idéia. No espectro político-ideológico oposto, da coalizão de direita, mais da metade dos deputados defendeu a ruptura do acordo de complementação econômica. 
TABELA 1 - POSIÇÃO DOS PARTIDOS CHILENOS EM RELAÇÃO AO PROJETO DE LEI INDICANDO DESLIGAMENTO DO ACORDO DE COMPLEMENTAÇÃO ECONÔMICA COM O MERCOSUL.

\begin{tabular}{|c|c|c|c|c|}
\hline \multirow{2}{*}{\multicolumn{2}{|c|}{ POSICIONAMENTO }} & \multicolumn{2}{|c|}{ COALIZÕES } & \multirow[b]{2}{*}{ TOTAL } \\
\hline & & C-ESQ & C.DIR & \\
\hline \multirow{3}{*}{ Favoráveis } & $N$ & 1 & 24 & 25 \\
\hline & $\%$ & 1,67 & 51,06 & 23,36 \\
\hline & r.a. & $.5,99$ & 5,99 & \\
\hline \multirow{3}{*}{ Contrários } & $N$ & 40 & 5 & 45 \\
\hline & $\%$ & 66,67 & 10,64 & 42,06 \\
\hline & r.a. & 5,83 & $-5,83$ & \\
\hline \multirow{3}{*}{ Abstençốes } & $M$ & 2 & 6 & 8 \\
\hline & $\%$ & 3,33 & 12,77 & 7.48 \\
\hline & r.a. & $-1,84$ & 1,84 & \\
\hline \multirow{3}{*}{ Não votaram } & $M$ & 17 & 12 & 29 \\
\hline & 8 & 28,33 & 25,53 & 27,10 \\
\hline & r.a. & 0,32 & $-0,32$ & \\
\hline Total (100\%) & & $60(100 \%)$ & $7(100 \%)$ & $107(100 \%)$ \\
\hline
\end{tabular}

NOTAS:

1. Com a sequinte representação: número de deputados, $\%$ por coluna e r.a. (resíduo ajustado, significativo se $>+2,00$ ou $<-2,00$ ). Qui-quadrado (pearson): 0,00 .

2. Deputados independentes não foram contabilizados (foram incluídos no sistema de missing).

Esses dados corroboram fortemente a tese da correlação positiva entre partidos de esquerda $\mathrm{e}$ apoio à integração sul-americana. É preciso que se faça, à luz dos dados acima, qualificações a idéias difusas de que as forças de centro-esquerda são mais propensas à integração sub-regional quando comparadas às forças de centro-direita do espectro político-ideológico. Na realidade, esquerda e direita suportam projetos substantivamente distintos de integração regional.

Dentre essas diferenças, a mais pronunciada diz respeito à disposição de se consolidar alianças assimétricas. Enquanto a esquerda defende a integração entre países em desenvolvimento, a direita tende a suportar integração com grandes potências. Além disso, a direita insiste numa integração comercial, de mercados, ao passo que a esquerda valoriza a integração política e societal.

A polarização esquerda-direita em torno dos acordos de livre-comércio também teve impacto no debate das eleições presidenciais mexicanas, realizadas em julho de 2006. Confrontaram-se, de um lado, o candidato de centro-direita Felipe
Calderón (Partido da Ação Nacional-PAN) e, de outro, o candidato de esquerda Lopez Obrador (Revolucionário Democrático-PRD). A candidatura de centro-direita representou as forças e grupos de interesse pró-livre-comércio, comprometidos com o aprofundamento das reformas liberais e com a manutenção do acordo de livre-comércio com EUA e Canadá (Nafta). Enquanto a candidatura de esquerda viria, caso tivesse vencido, a reforçar o eixo que vem sendo formado por líderes nacionalistas de esquerda, tais como Hugo Chávez (Venezuela), Fidel Castro (Cuba) e Evo Morales (Bolívia). Um dos alvos da implementação de uma política nacionalista seria precisamente a revisão de acordos do Nafta.

Esse fenômeno da polarização do debate político por conta de acordos comerciais também encontra paralelo na realidade brasileira. Tem sido recorrente a idéia de que a política externa foi a face mais ousada do primeiro mandato presidencial do governo petista. Diante de uma política macroeconômica ortodoxa e, como conseqüência, de políticas microeconômicas, os graus de liberdade para o exercício de uma política heterodoxa, com ressonância em setores de esquerda e outras forças nacionalistas, teriam sido maiores precisamente na política externa. Esta teria, portanto, figurado como uma espécie de asset $^{3}$ político, a fim de ampliar bases de apoio tanto no plano doméstico como internacional.

Foi no marco dessa inovação que o governo Lula defendeu a importância de uma política externa autônoma às grandes potências e rechaçou as grandes negociações comerciais do Mercosul com os EUA e a União Européia; amplificou contatos e parcerias de tipo Sul-Sul, via coalizões ou acordos bilaterais; instrumentalizou, de forma ainda mais assertiva do que os governos anteriores, a diplomacia presidencial e a imagem positiva de uma liderança de esquerda; proclamou disposição de liderança tanto no plano global quanto regional de forma a marcar diferenças da gestão anterior, tida como pouco assertiva no plano internacional; adensou alianças com países com agendas alternativas como a Argentina e a Venezuela; defendeu a expansão de uma agenda normativa no campo

\footnotetext{
3 Processo semelhante ao que teria ocorrido, guardadas as devidas proporções, durante o governo Jânio Quadros, conforme analisado em Fonseca Júnior (1998).
} 
multilateral com propostas de taxação transnacional para criação de fundos de desenvolvimento e erradicação da pobreza e da fome etc.

Contudo, não se pode conceber a política externa como autônoma à política macroeconômica e desconsiderar os conflitos de interesses estruturais entre essas duas dimensões. Com efeito, uma das grandes dificuldades da política brasileira de integração sub-regional tem sido a dificuldade em implementar um programa de integração de corte desenvolvimentista (keynesiano), com apoio, por meio de fundos estruturais, a economias menos desenvolvidas e com fomento de políticas industriais comuns. A ausência de políticas dessa natureza tem sido correntemente diagnosticada pelos países menores do Cone Sul, notadamente o Paraguai e o Uruguai, como uma das principais deficiências em termos de política que pudessem reduzir assimetrias presentes na integração sub-regional.

Algumas políticas pontuais, como a criação do Fundo para a Convergência Estrutural do Mercosul (Focem) e os projetos de financiamento de infraestrutura ${ }^{4}$ com financiamento por parte do Banco Nacional de Desenvolvimento Econômico e Social (Bndes) foram, na primeira gestão de Luís Inácio Lula da Silva, algumas das iniciativas na direção de uma política integrativa com face cepalina. Porém, a magnitude desses empreendimentos foi nitidamente desproporcional aos desafios determinados pelas assimetrias constitutivas da integração regional. E isso não se dá, por certo, por falta de sensibilidade política do governo petista. Na realidade, dá-se por uma dinâmica de soma zero que se estabelece entre políticas restritivas macroeconômicas de cunho liberal e políticas desenvolvimentistas, seja no campo doméstico, seja no campo internacional.

Ainda que o nacional desenvolvimentismo fosse a orientação em termos de projeto nacional, haveria conflitos deste projeto com a dinâmica de integração regional. $\mathrm{O}$ aparato conceitual do nacional-desenvolvimentismo centra-se na idéia da in-

\footnotetext{
4 Uma pesquisa realizada (survey junto a 100 líderes da região de diferentes segmentos) pelo Centro de Estudos de Negociações Internacionais (CAENI, 2005) mostra que a integração física é um dos importantes indutores positivos da integração regional.
}

tervenção estatal e industrialização induzida. Vêse, nesse esquema, a combinação da ênfase nos graus de liberdades dos instrumentos de formulação de política industrial e rechaço a compromissos internacionais que constranjam esses instrumentos com políticas comerciais restritivas, contrárias ao aprofundamento da abertura comercial. Regras sobre investimentos diretos estrangeiros, compras governamentais e direito de propriedade intelectual são alguns desses compromissos restritivos.

Este conflito estrutural, política nacional versus compromissos internacionais, impacta o cerne dos projetos integrativos sul-americanos, arena-chave ao exercício de uma política externa inovadora e progressista. Não resta dúvida de que a simultaneidade, na América do Sul, de governos de centro-esquerda ou progressistas reforça a convergência política e a prioridade em torno do projeto de integração ou governança sul-americana. Contudo, a forte propensão dos governos da região em manter graus de liberdade em termos de formulação de política industrial, dificulta os esforços de ação coletiva.

Outra qualificação deve ser feita à tese do vínculo direto entre posicionamento político de esquerda e apoio à integração regional. Trata-se da incorporação de uma dimensão freqüentemente deixada de lado nos esquemas analíticos sobre o tema da integração regional: o papel do nacionalismo como vetor da integração regional. Por suposto, o nacionalismo é antagônico ao internacionalismo, à supranacionalização de normas internacionais ${ }^{5}$. Isso tem impacto direto na instauração de matrizes institucionais supranacionais mínimas que podem servir como esteio de estabilidade a políticas forjadas no âmbito da integração regional. O que acaba como vimos por desaguar em abordagens intergovernamentalistas e desestabilizar o próprio processo de integração regional.

\footnotetext{
5 A pesquisa Caeni (OLIVEIRA \& ONUKI, 2005) corrobora a percepção de que posturas nacionalistas e populistas concorrem como um dos mais relevantes entraves à integração sul-americana. A pesquisa foi feita junto a lideranças da região (do meio acadêmico, empresarial, diplomático e de governo). Ante a pergunta "o senhor tem conhecimento de mudanças políticas ou institucionais que tenham dificultado ou contribuído para a integração sulamericana?", a resposta mais recorrente foi: "a emergência de regimes populistas na região".
} 
O nacionalismo pode, neste sentido, ser entendido como uma dimensão autônoma em relação ao espectro político. A refratariedade à cessão de soberania em prol da integração regional e da supranacionalização das normas é comum aos regimes nacionalistas de esquerda ou direita. Em que pese a inexistência de estudos conclusivos sobre a relação entre regimes políticos e políticas comerciais ${ }^{6}$, é ainda plausível considerar que, quanto mais centralizado for o processo decisório como, notadamente, no caso do presidencialismo plebiscitário, menor será a propensão em dividir capacidade regulatória, seja no sentido doméstico (ao Legislativo) seja no sentido internacional (a instâncias supranacionais).

De todo modo, é válido dizer que governos localizados no espectro liberal-conservador tendem a usar a abertura econômica como instrumento de ampliação de competitividade, manutenção da inflação em níveis reduzidos e instrumentos de credibilidade internacional como forma de atração de investimentos diretos estrangeiros. $\mathrm{Na}$ mesma direção estão as políticas de adoção de marcos reguladores atrativos de capital estrangeiro, adesão a compromissos internacionais restritivos de formulação de política industrial e doméstica, mas vistos como esquemas que reforçam reformas liberais (efeito de lock-in).

No outro espectro, governos nacional-progressistas tendem a adotar o protecionismo comercial como política de desenvolvimento econômico. Tomam como preocupação central o espaço de formulação de políticas (policy space). Essa preocupação explica o posicionamento refratário em relação à adoção de regras de investimentos protetoras do capital internacional, compromissos no campo de compras governamentais ${ }^{7}$ e propriedade intelectual etc.

\footnotetext{
6 Vários estudos procuraram estabelecer relações de causalidade e correlações entre regimes políticos e padrões de política comercial ou inserção internacional dos países, a exemplo de Ronald Rogowski (1987); Helen Milner e Peter Rosendorff (1997); Edward D. Mansfield, Helen Milner e Peter Rosendorff (2000). George Tsebelis (1997), em direção oposta, descarta correlações diretas entre regime político e resultados políticos ao afirmar que a produção e a estabilidade de políticas (inclusive de comércio) dão-se em função do número de vetos políticos do sistema político (veto player). Quanto mais pontos de vetos houver num sistema menor será a possibilidade de mudanças políticas.

7 A participação do setor público na economia é maior quanto mais intervencionista for o modelo econômico. Por
}

Soma-se a isto o fato de que os regimes presidencialistas plebiscitários tendem a ter menor propensão à supranacionalização de acordos comerciais ou, no limite, da internalização e cumprimento das regras internacionais estabelecidas ${ }^{8}$. É mais provável que governos nacionalistas tendam a privilegiar esquemas intergovernamentais de negociações internacionais, ao invés de adensamento das estruturas supranacionais estabilizadoras das decisões tomadas, ou de instauração de mecanismos de solução de controvérsias com efetivo poder de imposição das regras. Mais uma vez aqui o problema é com a refratariedade a ceder liberdade de manejos a políticas em prol de esquemas supranacionais de enforcement da integração regional.

A preferência de regimes com presidencialismo forte por esquemas intergovernamentais explica em grande medida o estado da arte da integração sul-americana. Nenhum dos processos integrativos sub-regionais foi bem sucedido em adensar a institucionalização supranacional, responsável por garantir bases mínimas de estabilidade das decisões acordadas. O Mercosul é um exemplo bem acabado desta realidade. A própria Comunidade Andina de Nações (CAN), até então considerada o mais denso esquema supranacional de integração, vem sofrendo retrocessos no campo da supranacionalização de normas.

sua vez, quanto maior for a participação de setores públicos na economia, mais intensos serão os efeitos da liberalização de compras governamentais e a reação doméstica à assunção deste tipo de compromisso. Na pesquisa coordenada pelo Caeni, nenhum dos países analisados é signatário do acordo de compras governamentais da OMC, com exceção do Chile. E todos possuem algum tipo de discriminação contra o ofertante estrangeiro ou, pelo menos, favorecem o uso de produtos produzidos nacionalmente (OLIVEIRA \& ONUKI, 2005).

8 Diferentemente da CAN, o Mercosul é tido como um modelo ad hoc, com baixo nível de institucionalização supranacional. Este modelo teve, em determinado momento, a vantagem de ser flexível, como no processo das negociações em torno da Tarifa Externa Comum. Por outro lado, a ausência de um corpo normativo supranacional com poder de enforcement é apontado como um sério entrave ao aprofundamento da integração do Mercosul. Já o modelo adotado pela CAN, de envergadura supranacional, apresenta inúmeros problemas e entraves institucionais, sobretudo no que se refere à implementação das normas (OLIVEIRA \& ONUKI, 2005). 
Com essas duas matrizes integrativas, Mercosul e CAN, é limitada a perspectiva de que a Comunidade Sul-Americana de Nações (CASA) possa servir de base a uma integração sul-americana efetiva. Uma expectativa era de que os modelos Mercosul e CAN caminhassem no sentido de uma convergência dos marcos normativos supranacionais.

A tese, portanto, de que a convergência de governos de esquerda e a eventual reeleição de Lula reforçam, inexoravelmente, a integração sulamericana precisa ser qualificada. $\mathrm{O}$ mais correto seria dizer que o cenário de reeleição de Lula deve tonificar a integração política sul-americana, cujo projeto se dá no marco da Comunidade Sul-Americana das Nações, principalmente no eixo político Argentina-Brasil-Venezuela, uma vez que países como a Colômbia tem sua dinâmica já voltada para o Norte.

De forma geral, o debate político na sucessão eleitoral de 2006 no Brasil esteve polarizado da mesma forma que em outros países. Igualmente ao que ocorreu no Chile, a aliança de centro-direita, capitaneada pelo Partido da Social-democracia Brasileira (PSDB), defendeu como posicionamento programático a reaproximação do país com as grandes potências no campo comercial. Uma das críticas correntes de representantes da aliança de centro-direita foi a de que posturas excessivamente defensivas por parte do governo brasileiro teriam minado negociações-chave com centros dinâmicos como os EUA (via negociações da Alca) e a União Européia (via negociação Mercosul-União Européia): opção política, ainda segundo discurso da centro-direita, em nome de alianças políticas do tipo Sul-Sul.

Talvez até para demarcar território próprio, a aliança de centro-direita no Brasil procurou mostrar contrastes com relação à política externa do atual governo no que tangia a um conjunto de temas. Tais como, a instauração de uma política externa mais ortodoxa e simpática às alianças com os EUA e a União Européia; o abandono da ênfase nas alianças Sul-Sul; maior ênfase nos aspectos comerciais da integração em detrimento de uma dinâmica mais comercial e de investimentos do que os aspectos políticos e sociais.

A aliança de centro-direita defendeu ainda mudanças no que toca ao desenho institucional de formulação e condução da política externa de for- ma geral, e da política comercial em particular. A referência e o modelo de reforma propugnado por esta aliança era o USTR norte-americano. Na base das críticas estaria o fato de que a atual política comercial tem sido o problema da dispersão e falta de coordenação decisória, além de um retrocesso do ponto de vista de canais institucionais de articulação entre governo e setor privado.

Outro aspecto da polarização da campanha política no Brasil teve a ver com a questão regulatória. Postada num campo político e econômico mais liberal, a aliança PSDB-PFL sinalizou disposição em reduzir a intervenção do Estado na Economia, ao lado da instauração de instrumentos regulatórios internacionais (como regras de investimentos e compras governamentais), anteriormente vistos como constrangimentos à execução de políticas industriais. Do mesmo modo, posicionou-se em favor da consolidação de agências reguladoras, capazes de servir de matriz não conflitiva com as regras regionais ou multilaterais de comércio.

\section{ESPECTRO POLÍTICO-IDEOLÓGICO E POLIITICA COMERCIAL: DISCUSSÃO}

O que se pôde observar pelas posturas dos partidos políticos ao longo do espectro ideológico, tomando três países como referência (Brasil, Chile e México) é de que a perspectiva da integração regional não pode ser derivada de uma dimensão única de análise. A combinação de várias dimensões é que indica as perspectivas e o modelo de integração a ser forjado.

Além disso, as forças partidárias tendem a apoiar políticas que, em uma dada dimensão, funcionam como indutoras positivas da integração, ao mesmo tempo em que apóiam políticas em outra dimensão que figuram como restritivas (ou de entraves) à integração regional.

Esta distribuição de preferências, num exemplo de duas dimensões, pode ser esquematizada tal como no figura 01 (abaixo). Partidos de centro-esquerda tendem a dar apoio mais intensivo à integração regional em sua dimensão política, sobretudo tratando-se de um esforço de ação coletiva que vise reequilibrar as relações com as grandes potências. Além disso, partidos neste espectro político tendem a ser mais favoráveis a políticas integrativas de tipo keynesiano, de investimentos estatais (ou mobilização) de fundos estruturais em prol da integração regional. 
Como aspecto restritivo, identificamos, no sentido oposto, a indisposição de regimes de esquerda populistas em ceder graus de manejo em termos de política industrial. Isso vale para instâncias domésticas - tais como reforço do papel do poder Legislativo em matéria de política comercial ou fortalecimento de burocracias autônomas, como, por exemplo, agências reguladoras ou o Banco Central. No plano externo, como decorrência, há uma refratariedade de institucionalização de regras no plano supranacional (binding), em benefício de esquemas intergovernamentais mais flexívies, porém menos garantidores de estabilidade de regras coletivistas.

As forças de centro-direita são mais propensas a políticas liberalizantes na arena comercial ou adjacente, que podem figurar como elementos indutores-chave dos processos integrativos. Vale citar, entre esses, a abertura comercial de acesso de seu próprio país como instrumento de integração (ou até como peça de políticas macroeconômicas monetaristas); a regulação mais favorável a transações comerciais (como por exemplo, regras de investimentos internacionais); a presença de desenhos institucionais que conferem mais estabilidade a regras comerciais; a propensão à supranacionalização de normas. Sobre este último item, não por outra razão, senão com a intenção de aprisionar reformas liberalizantes, governos de centro-direita no México, no Chile e mesmo no Brasil amarraram regulações nacionais em acordos internacionais, multilaterais ou regionais.

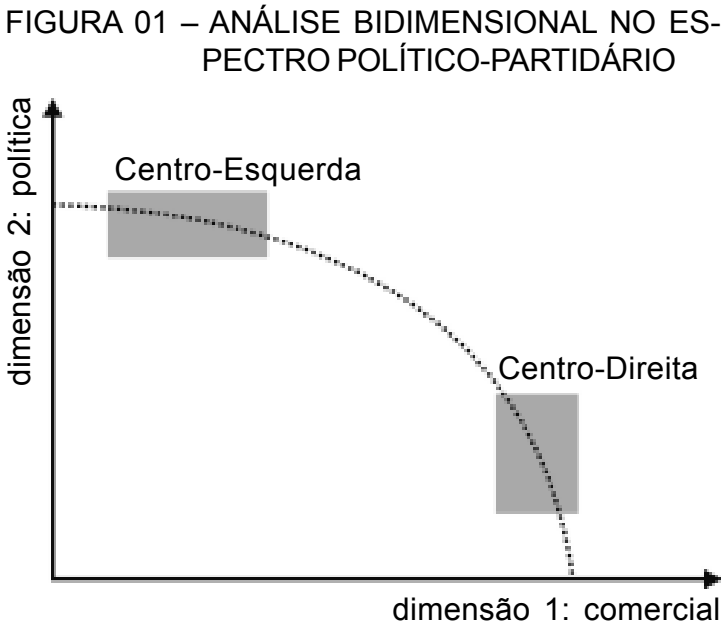

Assim, mais do que vaticinar correlações positivas entre governos de esquerda e perspectivas da integração regional, é preciso fazer uma análise por dimensões. Para então buscar predizer de que forma posturas ao longo do espectro ideológico podem servir como indutores positivos ou negativos da integração.

\section{CONCLUSÃO}

O que se viu, assim, no caso brasileiro e em outros países analisados (Chile e México), foi uma polarização quanto a tipos distintos de apoio a projetos de integração regional. Mas não propriamente, e necessariamente, uma correlação positiva entre governos de esquerda e perspectiva de consolidar a integração regional. Em ambos os espectros políticos, de centro-direita e de centro-esquerda, existem elementos catalisadores e entraves ao processo de integração regional.

Trata-se de projetos distintos, com tônus ora mais comercial, ora mais político; ora mais estatal, ora mais societal, e assim por diante. Há de se atentar, neste sentido, para que os estudos sobre processos integrativos latino-americanos passem a levar em conta também os aspectos relacionados aos regimes políticos, ao fenômeno do nacionalismo e às forças político-partidárias que operam no sistema político. Os impactos distributivos da integração na América Latina, com a consolidação do NAFTA (North American Free Trade Agreement) e de outros tantos acordos regionais, já se fazem sentir. A tal ponto que não se pode mais compreender preferências governamentais sem menção ao que se passa no jogo políticopartidário. E isso é, sem dúvida, uma grande novidade do ponto de vista da agenda de pesquisa. 
Janina Onuki (janonuki@caeni.com.br) é Professora de Relações Internacionais da Universidade Estadual Paulista (UNESP) e pesquisadora do Centro de Estudos das Negociações Internacionais da Universidade de São Paulo (Caeni-USP).

Amâncio Jorge de Oliveira (amancioj@usp.br) é Professor do Departamento de Ciência Política da Universidade de São Paulo (USP) e coordenador científico do Centro de Estudos das Negociações Internacionais da Universidade de São Paulo (Caeni-USP).

\section{REFERÊNCIAS BIBLIOGRÁFICAS}

ARROYO, S. R. 2004. Existencia y efectividad de las instituciones supranacionales andinas. Disponível em : http:// www.integra.cepal.org.br. Brasília : Comissão Econômica para a América Latina e o Caribe. Acesso em : 28.nov.2005.

BARDWELL, K. 2000. The Puzzling Decline in House Support for Free Trade : Was Fast Track a Referendum on Nafta? Legislative Studies Quarterly, Iowa, v. 25, n. 4, p. 591-610, Nov.

BUENO DE MESQUITA, B. 2000. Principles of International Politics : People's Power, Preferences and Perceptions. Washington, D. C. : CQ.

FONSECA JÚNIOR, G. 1998. A legitimidade e outras questões internacionais : poder e ética entre as nações. Rio de Janeiro : Paz e Terra.

GARRET， G. \& LANGE， P. 1996. Internationalization, Institutions, and Political Change. In : KEOHANE, R. \& MILNER, H. (eds.). Internalization and Domestic Politics. Cambridge : Cambridge University.

KEOHANE, R. \& MILNER, H. (eds.). 1996. Internalization and Domestic Politics. Cambridge : Cambridge University.

GAUBATZ, K. T. 1996. Democratic States and Commitment in International Relations. International Organization, Cambridge, Mass., v. 50, n. 1, p. 109-139, Winter.

HAGAN, J. 1995. Domestic Political Explanations in the Analysis of Foreign Policy. In : NEACK, L. (ed.). Foreign Policy Analysis : Continuity and Change in Its Second Generation. Miami : Miami University.

HATHAWAY, O. A. 1998. Positive Feedback: The Impact of Trade Liberalization on Industry Demands for Protection. International Organization, Cambridge, Mass., v. 52, n. 3, p. 575-612, Summer.

HENISZ, W. \& MANSFIELD, E. 2006. Votes and Vetoes : The Political Determinants of Commercial Openness. International Studies Quarterly, Malden, Mass., v. 50, n. 1, p. 189211, Mar.

MARKS, G.; HOOGHE, L.; NELSON, M. \& EDWARDS, E. 2006. Party Competition and European Integration in the East and West : Different Structure, Same Causality. Comparative Political Studies, Washington, D. C., v. 39, n. 2, p. 155-175, Mar.

MARKS, G.; WILSON, C. \& RAY, L. 2002. National Political Parties and European Integration. American Journal of Political Science, Bloomington, v. 46, n. 3, p. 585-594, Jul.

MANSFIELD, E.; MILNER, H. \& ROSENDORFF, P. 2000. Free to Trade : Democracies, Autocracies, and International Trade. American Political Science Review, Washington, D. C. , v. 94, n. 2, p. 305-321, June.

MILNER, H. \& ROSENDORFF, P. 1997. Democratic Politics and International Trade Negotiations : Election and Divided Government as constraints on trade liberalization. Journal of Conflict Resolution, New Haven, v. 41, n. 1, p. 117-146, Feb.

MILNER, H. \& YOFFIE, D. 1989. Between Free Trade and Protectionism : Strategic Trade Policy and a Theory of Corporate Trade Demands. International Organization, Cambridge, Mass., v. 43, n. 2, p. 239-272, Spring.

OLIVEIRA, A. 2003. Legislativo e política externa : das inconveniências da abdicação. Série Working Papers, São Paulo, n. 3, nov. 
OLIVEIRA, A. \& ONUKI, J. (orgs.). 2005. Entraves e possibilidades institucionais e políticos da integração regional sul-americana. Estudos e Cenários, Rio de Janeiro.

REMMER, K. 1998. Does Democracy Promote Interestate Cooperation? Lessons from the Mercosur Region. International Studies Quarterly, v. 42, n. 1, p. 25-51, p. 25-52, Mar.

RIBEIRO P. F. (org.). 2006. Base de dados do Centro de Estudos das Negociações Internacionais (Caeni). São Paulo : Centro de Estudos das Negociações Internacionais.

ROGOWSKI, R. 1999. Institutions as Constraints on Strategic Choice. In : LAKE, D. \& POWELL, R. (eds.). Strategic Choice and International Relations. Princeton : Princeton University.

SANTOS, F. 2006. Integração regional e as eleições presidenciais de 2006 no Brasil. Análise de Conjuntura, Rio de Janeiro, n. 2, fev.

SIMMONS, B. 2000. International Law and State Behavior : Commitment and Compliance in International Monetary Affairs. The American Political Science Review, Washington, D. C., v. 94, n. 4 , p. $819-835$, Dec.

SOARES DE LIMA, M. R. \& COUTINHO, M. 2006. Integração moderna. Análise de Conjuntura, Rio de Janeiro, n. 1, jan.

SOARES DE LIMA, M. R. \& SANTOS, F. 2001. O Congresso e a política exterior. Lua Nova, São Paulo, n. 52, p. 121-150.

TSEBELIS, G. 1995. Processo decisório em sistemas políticos : veto players no presidencialismo, parlamentarismo, multicameralismo e pluripartidarismo. Revista Brasileira de Ciências Sociais, São Paulo, v. 12, n. 34, p. 89-117, jun.

2001. The Institutional Foundations of Intergovernamentalism and Supranationalism in the European Union. International Organization, Cambridge, Mass., v. 55, n. 2, p. 357-390.

2002. Veto Players : How Political Institutions Work. New York : Russell Sage Foudation.

VERDIER. D. 1998. Democratization and Trade Liberalization in Industrial Capitalist Countries. Comparative Studies in Society and History, Cambridge, Mass., v. 40, n. 4, p. 587-608, Oct. 